\title{
Therapeutic Effects of Sansevieria Trifasciata Ointment in Callosities of Toes
}

\author{
Hamidollah Afrasiabian ${ }^{1}$, Reza Hododi ${ }^{2}$, Mohammad Hadi Imanieh ${ }^{1}$ \& Alireza Salehi ${ }^{1}$ \\ ${ }^{1}$ Research Center for Traditional Medicine and History of Medicine, Shiraz University of Medical Sciences, \\ Shiraz, Iran \\ ${ }^{2}$ Medicinal herbs group higher Institute of Applied Science Agriculture Hamedan, Iran \\ Correspondence: Hamidollah Afrasiabian, MD, Ph.D. in Iranian Traditional Medicine, Research Center for \\ Traditional Medicine and History of Medicine, Shiraz University of Medical Sciences, Shiraz, Iran. Tel/Fax: \\ 98-71-3233-7589. E-mail: afrasiabian@sums.ac.ir
}

Received: June 9, 2016 Accepted: July 6, 2016 Online Published: July 22, 2016

doi:10.5539/gjhs.v9n2p264 URL: http://dx.doi.org/10.5539/gjhs.v9n2p264

\begin{abstract}
Currently study was a double-blind clinical trial in terms of ointments with different contents and the variables such as sex, drug charges, occupation, age, number of lesions, patients, lesions location, time of manifestation, lesion size and methods of treatment and recovery time. In addition, total patients under studied were 100 people in dermatology clinic of Farshchian hospital of Hamadan in Iran that they were divided into two groups. The first group (A) contained of 68 individual who were divided into three groups which used sanseveria extract with different percentage of containing 5, 10, and 20\%. Further, the second group (B) included 32 patients who used from other methods of treatment were divided into three groups. In one group12 patients have been treated by using salicylic acid, in the other groups 12 individuals used from electro cautery and 8 patients were used of the corn plasters method. In addition, 116 patients in this study were in the range of 7 to 57 years of age. In fact 100 of them have used the drug correctly while 16 patients were excluded due to wrong usage. Also the plant (Sansevieria Trifasciata) was prepared in Hamedan Research Center from plant by dried extracts method. Finally, the results were analyzed statistically using SPSS software. In conclusion, based on the results of significant impact on the treatment of corns, all patients $(100 \%)$ in the first group have been treated, additionally all participants in the study were improved within 4 weeks such that the recovery time for the $5 \%$ ointment was 25 days, while for $10 \%$ and $20 \%$ ointment was 15 and 10 days respectively.
\end{abstract}

Keywords: medicinal plants, sansevieria, corn lesion, herbal medicine, traditional medicine, complementary medicine

\section{Introduction}

Skin is one of the most sensitive areas of the body that react to the slightest pressure and the reaction is manifested as different ways such as swelling, redness, blisters and even corns, which is a natural reaction caused by the body to protect itself (Fitz Patrick, 1993). Moreover corns generally occur on the tops and sides of the toes. A hard corn is a small patch of thickened, dead skin with a small plug of skin in the centre. A soft corn has a much thinner surface, appears whitish and rubbery, and usually occurs between the toes. Seed corns are clusters of tiny corns that can be very tender if they are on a weight-bearing part of the foot. Seed corns tend to occur on the bottom of the feet, and some doctors believe this condition is caused by blocked sweat ducts (Coughlin, 2000).

Corns are more likely to patients in people with bone disorders or having damaged glands or wounds and corns on their feet as well as those with diabetes or poor circulation in the legs (Hollingsworth, 1995). One of the usual and common treatments is use of compounds of salicylic acid and lactic acid $16.7 \%$ in collodione body that is considered as the first choice for the treatment of common and plantar corns. Of course, daily and long-term use may be effective in only $60-70 \%$ of cases. Sometimes other treatments are used for treatment of corns with a type of resin used in medicine such as Podophyllin and cytotoxic compounds that are prescribed to the treatment of corns. Other alternative treatments that are done for genital corns include electro-cautery (burning with cautery), freezing, laser and so on (Sterling et al., 2001; Gibbs et al., 2002). Use of medicinal plants has been experienced to treat diseases for centuries. Today, notwithstanding that the majority of drugs are chemical, it was 
estimated that at least one third of all pharmaceutical products have plant originated or modified after extraction from plants (Yaqub, 1979). Plants traditionally were used to treat various diseases and skin diseases. Even, sometimes the treatment was considered as basic method (Zargari, 1995). Today, herbal medicine with remedies and medicinal plants have a great interest and one of the new approaches to medicine is use of plants in order to prevent of disease and basic treatment or supplements for physical illness (Amin, 1991).

Sansevieria trifasciata is a tropical plant that grows in the land of Africa from East of Nigeria to Congo and Southeast Asia and is an evergreen plant and accounted as a popular home life plants, Sansevieria trifasciata also called viper's bowstring hemp (Coughlin, 2000). Like some other members of its genus, Sansevieria yields bowstring hemp, a strong plant fiber once used to make bowstrings so that It is now used predominantly as an ornamental plant, outdoors in warmer climates, and indoors as a houseplant in cooler climates (Smith, 1941). A study by NASA found that it is one of the best plants for improving indoor air quality by passively absorbing toxins such as nitrogen oxides and formaldehyde (Csurhes \& Edwards, 2006). Sansevieria trifasciata is considered by some authorities as a potential weed in Australia, although widely used as an ornamental, in both the tropics outdoors in both pots and garden beds and as an indoor plant in temperate areas. The plant contains Saponins which are mildly toxic to dogs and cats and can lead to gastrointestinal upset if consumed (Csurhes \& Edwards, 2006).

In ancient times according to traditional medicine, this plant has been used due to their medicinal properties to fiber preparation and sometimes its leaves were used for wound dressings (Mimaki et al., 1997). Also Sansevieria trifasciata is commonly known as snake plant or mother in-law's tongue, an evergreen herbaceous perennial plant found throughout Malaysia (Sunilson et al., 2009) and has been traditionally used by Orang Asli in Perak, Malaysia for the treatment of ear pain, swellings, boils and fever. In summary to the best of our knowledge we could not find such this research for curing corn by using Sansevieria therefore, according to the characteristics of this plant, the main purpose of the present study was to evaluate the survey of therapeutic effect of Sansevieria Trifasciata in terms of ointment on corn and comparing it with the conventional chemical treatments.

\section{Methods}

\subsection{Study Design}

The current study was a randomized, controlled and double-blind clinical trial has been conducted to investigate the therapeutic effect of Sansevieria Trifasciata on corns in 2013 between Januarys to March at dermatology clinic of Farshchian Hospital, Hamedan City, Iran.

\subsection{Study Population}

Measure of entry into the study was including lacking of pregnancy, lactation and the lack of regular follow-up visit, no history of drug use and no infection in the fingers or adjacent corns while exclusion criteria included unwillingness to continue cooperation with the research treatment, not proper use of, having the same time prevent disease treatment, away from the study area, oral or topical antibiotics and lack of follow-up.

\subsection{Sample Determination}

This research during the Januarys to March 2013 by 116 patients who suffering from corn fingers referred to the dermatology clinic of Farshchian Hospital were studied, by the way 16 patients were excluded due to lack of conditions. Finally the remaining 100 individual based on population and consumption of drugs was divided into two groups. The first group (A) contained of 68 individual whom they have been divided into three group which used Sansevieria extract with different percentage of containing 5, 10, and 20\%. Likewise, the second group (B) was 32 patients who divided into three parts including 12 patients used salicylic acid, in the other group 12 individuals treated by electro cautery and 8 patients have been treated by Corn plasters method.Furthermore, in the first group the ointments with different content were prepared and prescription an examiner who the studied patients had no idea of the type of prescribed treatment. In addition, the containers of drugs have same shape and marked by number when administration, how to precision use of drug and put it on the lesion by a caliper after putting ointment around the corn for 6 weeks were taught to patients by trained experts. To summarized they were told to avoid the local to contact with any means or things until drug drying, and refer to dramatist if any complication such as severe local allergy symptoms.

\subsection{Preparation of Sanseveria Ointment}

To perform this test needed fresh herbs were prepared in Hamedan Research Center and the fresh plant was extracted by $70 \%$ alcohol and raw and active materials was extracted, Then extracts were filtered and concentrated as possible as by rotary vacuum distillation unit and were stored to investigation of therapeutic 
effect to improve corns (Fakhri, 2007) as dried and its dried extract were prepared using the cream base (Farabi company) in ointments with different contents of 5\%,10\% and $20 \%$ and were analyzed in special container in 15 $\mathrm{g}$ in weight. For evaluation and the time affecting of herbal drugs the registration was done in questionnaire containing the questions prepared by the researcher, with the help of advisors and used resources and was completed by a trained expert. Informed consent form was used for patients to use herbal to participate in this study. Provisions of having random sequences based on inclusion criteria were selected. At first, the patients who have corns were recognized by dermatologist in Farshchian Hamedan Hospital. At this stage, take an image on the area of the corns and the lesions were measured using a caliper. When administration, how to precision use of drug and put it on the lesion were taught to patients by trained experts. The number of medication use was 6 weeks, twice daily a small amount of ointment placed on the corn's location and dressed by bandage. Every week the patients were visited in Farshchian hospital and the size of the corns was measured again and was recorded in a questionnaire designed. After completing and recording the results, comparing the data was analyzed using the SPSS software versions 16.

\subsection{Statistical Analysis}

Statistical analysis was performed using SPSS software16 (SPSS Inc, Chicago, IL, USA).

\section{Result}

The total under studied patient (100 patients) in the Farshchian hospital $68 \%$ men and $32 \%$ of them were female. The age of participants ranged from 7 to 57 years old. From a sociological point of view, there was no significant difference between patients ( $\mathrm{p}=.649)$. In this study, a total of $32 \%$ of patients were treated from other methods of treatment include acid Salicylic 12\%, electro cautery technique $12 \%$ and Corn plasters $8 \%$. In this study, the drug was available at different contents of 5, 10 and $20 \%$.

In this study, $36 \%$ of those surveyed were students and educated that $80 \%$ their lesion location was on Toe. Further $60 \%$ of the subjects in this study have lesions more than one case so that the size of each lesion was different. Most patients have lesion size from 2 to $4 \mathrm{~mm}$ and the incidence of lesions in patient was different and varied from 1 month to 2 months with feeling their pain. In the study, which treatment period was defined for 6 weeks, full recovery of patient not reach to defined time and participants were recovered in the fourth week. There wasn't observed adverse effects on every under studied patients.

Table 1. Time recovery in corns for group A by different concentration of Sanseveria ointment

\begin{tabular}{lll}
\hline Concentration of Sanseveria ointment (\%) & The amount of patient treated (\%) & Time recovery (days) \\
\hline 5 & 24 & 25 \\
10 & 38 & 15 \\
20 & 8 & 10 \\
\hline
\end{tabular}

\section{Discussion}

According to statically analysis P-value between groups $(\mathrm{p}=.032)$ showed that the treatment is effective for a more detailed review of the impact we estimate, Statistical analysis was performed to lowest group(corn plaster), studies show that the sanseveria and electro cuter were the most effective methods. Furthermore, the greatest impact was seen in the group Sansevieria $(\mathrm{p}=.023)$ while the second was electro-cautery $(\mathrm{p}=.043)$ by the way two other methods are not effective in terms of $p$-value $(\mathrm{p}=.922)$. Finally the following table summarizes the success of treatment and statistical analysis based on P-value.

Table 2. Comparing all methods for curing corn by using P-value

\begin{tabular}{llll}
\hline Groups & Population(Person) & Successful treatment (\%) & $\begin{array}{l}\text { P-value compared } \\
\text { to minim groups }\end{array}$ \\
\hline Salysilic acid & 12 & 41.6 & .922 \\
Electro cauter & 12 & 83.3 & .043 \\
Corn PAD & 8 & 33.3 & - \\
Sanseveria ointment & 68 & 100 & .023 \\
P-value between groups & & & \\
\hline
\end{tabular}


In conclusion, based on the results of significant impact on the treatment of corns, all patients $(100 \%)$ in the first group have been treated, additionally all participants in the study were improved within 4 weeks such that the recovery time for the 5\% ointment was 25 days, while for $10 \%$ and $20 \%$ ointment was 15 and 10 days respectively. While the success rate in treatment in the second group was $41.6 \%$ for salicylic acid and $83.3 \%$ for electro cautery and $33.3 \%$ for corn plasters. Particularly the findings showed that the extract of Sansevieria Trifasciata has been affected in the treatment of callosities of fingers and toes.

Today medicinal plants are worthy replacement as environmental innovation in the medical field for chemical drugs. One of the major causes of the alternative is minimum side effects than chemical drugs (Hashemloian Delnavaz, 2010). According to the evidence found in this study, the mechanism is most likely the result of effective compounds of Sansevieria plant extracts which is considered as mainly good acidity with type of organic acids and also compatible with the skin. Further, the active compounds are penetrated in the corn within 2 to 3 days to remove corn's roots and then lead to repair of the skin. Even in this study, the effects of other drugs, such as skin lightening and exfoliating properties have been seen and this drug can be used for these cases. In previous studies that conducted for corn with acid salicylic, the effects were good but a problem that is seen in the salicylic acid the trace of corn is maintained due to burn after treatment, but the herbal medicine has not side effects and does not remain any complications. However, electro cautery treatment is quite effective but in 15 to 20 percent of treatment process the corn grows twice by using salicylic acid skin irritation and patient response sometimes seen. Also another problem in a number of cases is size reduction only. In conclusion Sansevieria as a unique method that can be good alternative for corn treatment, additional in the case of mass production Sansevieria extract treatment costs will be lower compared to other methods so that medical expenses should be considered in treatment methods of such patients. To summarize the different concentrations of Sansevieria extracts were prepared as our goal was to understand if increase in the concentration irritate patient skin and other objective was to examine the impact of the concentration on reducing recovery time. Fortunately, in both cases the answer was positive increasing the concentration did not cause irritation and increasing concentrations reduced recovery time.

\section{Conclusion}

Traditional and complementary medicine in particular, the plant therapy is one of the valuable assets of Medicine in Iran and Iran is one of three countries where philosophy and heritage of these plans has been existed. Due to side effects and damaging some chemical drugs, many patients are brought for treatment to the plant therapy; on the other hand, despite modern medicine capabilities and its value in the treatment of some diseases, especially chronic diseases there are some problems. In fact, statistics using herbal medicines is remarkable, especially in recent years. As a general rule, this drug has fewer side effects than other medications and drugs, of course there are exceptions in this regard (Ernst, 2005). Chronic diseases and problems associated with it should be more considered at future (Feng et al., 2005).

Our goal in this research was the use of indigenous knowledge of medicinal plants to find novel medicine for treatment of corn lesion. It seems that this drug is a good case for future investigation in viral and bacterial of skin infection.

\section{Acknowledgements}

This paper has been adopted during Hamidollah Afrasiabian's Ph.D. research period in Research Center for Traditional Medicine and History of Medicine, Shiraz University of Medical Sciences, Shiraz, Iran and dermatology clinic of Farshchian Hospital, Hamedan City, Iran. Additionally author to have gratefully appreciate from Dr. Keyvan Razaghi.

\section{Competing Interests Statement}

The authors declare that there is no conflict of interests regarding the publication of this paper.

\section{References}

Amin, G. (1991). Traditional medicinal plants of Iran. Ministry of Health and Medical Education Press, 1, 64-65.

Burns, D. A. (2008). Comparative Dermatology (pp. 27-44). Rook's Textbook of Dermatology, Blackwell Publishing, Inc.

Coughlin, M. J. (2000). Common causes of pain in the forefoot in adults. Journal of Bone and Joint Surgery-British, 82(6), 781-790. PMID: 10990297. http://dx.doi.org/10.1302/0301-620X.82B6.11422

Csurhes, S., \& Edwards, R. (2006). Potential environmental weeds in Australia: Candidate species for preventative control. Queensland Department of Natural Resources. 
Ernst, E. (2005). The efficacy of herbal medicine-an overview. Fundamental \& clinical pharmacology, 19(4), 405-409. PMID: 16011726. http://dx.doi.org/10.1111/j.1472-8206.2005.00335.x

Fakhri, S. (2007). Antibacterial effects of extracts licorice root, marshmallow, mallow plant and several others of the Nocardiosis. Islamic doctoral dissertation, Azad University School of Pharmacy.

Feng, C., Zhang, L., \& Liu, X. (2005). Progress in research of aldose reductase inhibitors in traditional medicinal herbs. Zhongguo Zhong Yao Za Zhi. China journal of Chinese materia medica, 30(19), 1496-1500. PMID: 16335816

Fitz Patrick, T. B. (1993). Dermatology in General Medicine (Vol. 2).

Gibbs, S., Altman, D. G., Harvey, I., Sterling, J., \& Stark, R. (2002). PapersLocal treatments for cutaneous warts: Systematic review Commentary: Systematic reviewers face challenges from varied study designs. $B M J$, 325(7362), 461. http://dx.doi.org/10.1136/bmj.325.7362.461

Hashemloian Delnavaz, B. A. A. A. (2010). Medicinal and edible plants. The first national conference on new issues in agriculture Saveh, Iran.

Hollingsworth, T. (1995). The incidence of warts and plantar warts amongst school children of East Anglia. Med Officers, 55-59.

Mann, R. A. (1987). Pain in the foot: 1. Evaluation of foot pain and identification of associated problems. Postgraduate medicine, 82(1), 154-162. http://dx.doi.org/10.1080/00325481.1987.11699903

Mimaki, Y., Inoue, T., Kuroda, M., \& Sashida, Y. (1997). Pregnane glycosides from Sansevieria trifasciata. Phytochemistry, 44(1), 107-111. http://dx.doi.org/10.1016/S0031-9422(96)00477-3

Smith, W. W. (1941). Sanseviekia, Google Patents.

Sterling, J., Handfield-Jones, S., \& Hudson, P. (2001). Guidelines for the management of cutaneous warts. British Journal of Dermatology, 144(1), 4-11. http://dx.doi.org/10.1046/j.1365-2133.2001.04066.x

Sunilson, J., Jayaraj, P., Varatharajan, R., Thomas, J., James, J., \& Muthappan, M. (2009). Analgesic and antipyretic effects of Sansevieria trifasciata leaves. African Journal of Traditional, Complementary and Alternative Medicines, 6(4).

Yaqub, A. (1979). Materia Medica and medicinal plants in Iran. Tehran, Tehran University Press.

Zargari, A. (1995). Medicinal plants. Tehrari University Publications.

\section{Copyrights}

Copyright for this article is retained by the author(s), with first publication rights granted to the journal.

This is an open-access article distributed under the terms and conditions of the Creative Commons Attribution license (http://creativecommons.org/licenses/by/3.0/). 